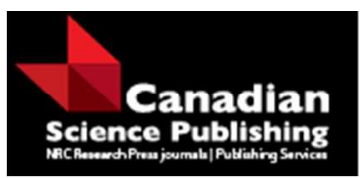

Canadian Journal of Forest Research Revue canadienne de recherche forestière

\title{
Genetic Resistance to White Pine Blister Rust in Limber Pine (Pinus flexilis): Major Gene Resistance in a Northern Population
}

\begin{tabular}{|r|l|}
\hline Journal: & Canadian Journal of Forest Research \\
\hline Manuscript ID & cjfr-2016-0128.R1 \\
\hline Danuscript Type: & Note \\
\hline Complete List of Authors: & $\begin{array}{l}\text { Sniezko, Richard; USDA Forest Service } \\
\text { Danchok, Robert; USDA Forest Service, Dorena Genetic Resource Center } \\
\text { Savin, Douglas ; USDA Forest Service, Dorena Genetic Resource Center } \\
\text { Liu, Jun-Jun; Canadian Forest Service, National Resources Canada, Pacific } \\
\text { Forestry Centre } \\
\text { Kegley, Angelia; USDA Forest Service, Dorena Genetic Resource Center }\end{array}$ \\
\hline Keyword: & $\begin{array}{l}\text { major gene resistance, Cronartium ribicola, limber pine, blister rust, Pinus } \\
\text { flexilis }\end{array}$ \\
\hline &
\end{tabular}

\section{SCHOLARONE ${ }^{\text {m }}$}

Manuscripts 
1 Genetic Resistance to White Pine Blister Rust in Limber Pine (Pinus flexilis): Major Gene 2 Resistance in a Northern Population

3

4 Richard A. Sniezko ${ }^{1 *}$, Robert Danchok ${ }^{1}$, Douglas P. Savin ${ }^{1}$, Jun-Jun Liu ${ }^{2}$, Angelia Kegley $^{1}$

$5 \quad{ }^{1}$ USDA Forest Service, Dorena Genetic Resource Center, 34963 Shoreview Road, Cottage

6 Grove, Oregon, 97424, U.S.A (rsniezko@fs.fed.us; rdanchok@,fs.fed.us; dpsavin@,fs.fed.us;

7 akegley@,fs.fed.us)

$8{ }^{2}$ Pacific Forestry Centre, Canadian Forest Service, Natural Resources Canada, 506 West

9 Burnside Road, Victoria, BC, V8Z 1M5, Canada, jun-jun.liu@,canada.ca

10 * Corresponding, email: rsniezko@fs.fed.us, Phone: (541) 767-5716, Fax: (541) 767-5709

11 


\section{Abstract}

13 Limber pine, Pinus flexilis, a wide-ranging tree species in western North America, is highly

14 susceptible to white pine blister rust (WPBR), caused by the non-native fungal pathogen

15 Cronartium ribicola. The Canadian populations in particular have been heavily impacted, and in

162014 limber pine was designated Endangered in Canada by COSEWIC. Little is known about

17 genetic resistance to WPBR in limber pine, but major gene resistance (MGR) has been

18 characterized in some populations in the U.S.A. This study examines resistance in seedling

19 families from 13 parent trees from British Columbia, Alberta and Oregon, representing the

20 northern and northwestern-most populations. Most families were susceptible with 100\% of the

21 seedlings cankered, but one family from Alberta segregated 1:1 for cankered and canker-free.

22 This is the first report of (a) MGR in Canada of any of the four species of five-needle pines

23 native to Canada, and (b) any resistance in limber pine in Canadian populations, and is the

24 northern-most known incidence of putative R-gene resistance in a natural stand of any five-

25 needle pine species. Many of the Canadian selections were from stands with high incidence of

26 WPBR infection, and their high susceptibility in this trial suggests that further infection and

27 mortality is likely in the Canadian populations.

28 Keywords: major gene resistance, Cronartium ribicola, Pinus flexilis, limber pine, white pine 29 blister rust 
32 Limber pine (Pinus flexilis James) is a wide-ranging forest tree species, occurring from southern

33 California in the United States to British Columbia and Alberta in Canada (Fig. 1). It occurs at

34 elevations ranging from 850 to $3810 \mathrm{~m}$, in a wide variety of habitats from subalpine to upper

35 alpine tree line (Steele 1990; COSEWIC 2014; Tomback and Achuff 2010). Limber pine is

36 highly susceptible to white pine blister rust (WPBR), caused by the non-native fungal pathogen

37 Cronartium ribicola J.C. Fisch (Smith et al. 2013). Other threats to this species include habitat

38 loss due to fire suppression and climate change as well as mortality from mountain pine beetle

39 (Dendroctonus ponderosae Hopkins) (Tomback and Achuff 2010). In the Canadian portion of its

40 range, limber pine was designated Endangered in November 2014 by the Committee on the

41 Status of Endangered Wildlife in Canada (COSEWIC), and since 2009 it has been designated

42 Endangered under Alberta's Wildlife Act (Government of Alberta 2014). A species recovery

43 plan is in place in Alberta (Alberta Whitebark and Limber Pine Recovery Team 2014).

44 Limber pine has been affected in much of its range by WPBR infection and mortality (Schwandt

45 et al. 2010). In Canada WPBR incidence is notably high, with many pine populations with

46 greater than 60 percent infection and over 40 percent mortality (Smith et al. 2011; 2013). The

47 ultimate deterioration and possible extirpation of these populations by WPBR will depend on

48 factors such as conducive environmental conditions for disease spread and intensification, levels

49 of natural regeneration of limber pine, and frequency of durable genetic resistance to WPBR in

50 extant populations.

51 The maintenance of limber pine as a viable species component in forest stands in much of its

52 range will be heavily dependent on the frequency and types of genetic resistance to WPBR and 
53 the geographic distribution of resistance. Maintaining genetic diversity within the species will

54 also be important. On sites of high WPBR hazard, the best chance for successful restoration

55 efforts will be dependent on the availability of seedlings with genetic resistance to WPBR.

56 However, relatively little is known for limber pine about the types of resistance to WPBR and

57 their frequency, and previous testing has encompassed only a small portion of the species'

58 geographic range (Schoettle et al. 2014). In earlier tests at Dorena Genetic Resource Center

59 (DGRC), limber pine from some populations in southern Wyoming to southern Colorado had

60 major gene (MGR) or R-gene resistance (Schoettle et al. 2014; Kinloch and Dupper 2002).

61 Major gene resistance restricts infection to the needles, and progeny of open-pollinated parent

62 trees heterozygous for MGR segregate in a 1:1 ratio for cankered and canker-free seedlings. In

63 this study we report on the first examination of half-sib families from populations of limber pine

64 from both Canada (BC and $\mathrm{AB})$ and Oregon for resistance to WPBR. These populations are

65 hundreds of kilometers from areas previously documented to have the $\mathrm{Cr} 4$ gene associated with

66 the MGR in limber pine in southern populations of the species. To our knowledge this is the first

67 WPBR testing of half-sib families of individual parent trees of limber pine from these three

68 geographic areas.

\section{Materials and Methods}

70 Open-pollinated progeny of five parent trees from Alberta, five from British Columbia, and three

71 from Oregon were included in a WPBR resistance test at Dorena Genetic Resource Center,

72 Cottage Grove, Oregon, U.S.A. The Canadian seedlots represent the northern extent of the

73 species range, while the Oregon seedlots represent the most northwestern population of the

74 species (Fig. 1). Seed from all but one of the Canadian parent trees were collected in 2010 and

75 2011; the other Canadian parent had seed collected in 1999. All of the Oregon parent trees had 
seed collected in 2013. The British Columbia and Alberta seedlots originated from six populations, with one or two parent trees per population. The two parents from Prairie Bluff were prostrate shrubs, less than $0.5 \mathrm{~m}$ tall. Previous surveys have noted the level of WPBR to be very high, 82, 94, and 96 percent in or near one British Columbia and two Alberta populations (Crowsnest Pass, Prairie Bluff, and Kananaskis, respectively) and low (0 to 13 percent) in the Abraham Lake population (Jodie Krakowski, personal communication, 2016). WPBR was present, but at undocumented levels, in the other British Columbia populations (Don Pigott, personal communication, 2016). An inactive canker was noted on the Kananaskis parent tree; WPBR infection was noted on both Crowsnest Pass parent trees, and previous records noted an inactive canker on Andy Good Creek \#151 (Don Pigott and Barb Gass, personal communication, 2016). The three Oregon seed collections were from parent trees on the Eagle Cap Ranger District of the Wallowa-Whitman National Forest. No WPBR infection was noted in the Oregon population during cone collection (Andy Bower, personal communication, 2016).

Seed were placed into stratification at $2^{\circ} \mathrm{C}$ on 1 April (Oregon seedlots) and 7 May 2014 (Canadian seedlots). Stratified seed from the Oregon lots were placed in the germinator on 17 May 2014, and seed began to germinate on 19 May. Stratified seed from the Canadian lots were placed in the germinator 9 June 2014 and began germinating 12 June. Germinated seed were transplanted into Ray Leach cone-tainers $\left(164 \mathrm{~cm}^{3}\right)$ in an unheated greenhouse. Prior to inoculation, seedlings were placed into a randomized complete block design, with three blocks and up to eight seedlings per family per block in row plots; most families had 21 seedlings, one family had only 17 seedlings, and one family had 22 seedlings (Table 1). All of the young seedlings had cotyledons and primary needles present, and 44 of the 270 seedlings (16 percent) also had secondary needles. 
99 Inoculation followed standard Dorena Genetic Resource Center protocols (Sniezko et al. 2011).

100 Seedlings were moved into the inoculation chamber on 8 September 2014 to acclimate.

101 Concurrently, native Ribes hudsonianum var. petiolare (an alternate host for WPBR) leaves

102 naturally infected with $C$. ribicola were collected from areas near whitebark pine and limber pine

103 on the Wallowa-Whitman National Forest. In late afternoon on 11 September, the infected Ribes

104 leaves were placed on wire screens above the pine seedlings at DGRC, telial side down, to

105 release basidiospores. Spore fall was monitored at periodic intervals by examining spore density

106 on microscope slides placed among the seedlings. The chamber was maintained at approximately

$107 \quad 16.7^{\circ} \mathrm{C}$ and $100 \%$ relative humidity during seedling acclimation and spore fall. Ribes leaves were

108 removed once the target spore density of 10,000 spores $/ \mathrm{cm}^{2}$ was observed on the monitoring

109 slides, approximately 10.5 hours after the Ribes leaves were placed over the pines. Once the

110 target inoculum density was reached for the last frame, the temperature was raised to $20^{\circ} \mathrm{C}$ and

111 relative humidity maintained at $100 \%$ to promote germination of the basidiospores; the seedlings

112 were left in the inoculation chamber approximately 48 hours to promote spore germination and

113 needle infection. The seedlings were removed from the chamber on 14 September and returned

114 to the unheated greenhouse for the duration of the trial. Actual spore density for the trial,

115 assessed from slides after the infected Ribes leaves were removed, averaged 10,740 spores $/ \mathrm{cm}^{2}$

116 (with rep means ranging from 9600 to 12,400 spores $/ \mathrm{cm}^{2}$ ), and basidiospore germination,

117 assessed on agar plates, was noted at 100 percent.

118 Assessments of seedling infection started after needle spots were visible on most seedlings.

119 Seedlings were assessed four times for disease symptoms and mortality: 28 January, 2 March, 23

120 April and 19 November 2015. Each seedling was evaluated for spot type (a) normal yellow,

121 susceptible (non-MGR) spots, (b) spots with necrotic bands or brown necrotic spots usually 
122 associated with MGR (Schoettle et al. 2014), or (c) indeterminate spot type, as well as three

123 categories of spot counts ( 0 spots; 1 to 10 spots; more than 10 spots), canker class (none;

124 possible canker; probable canker; definite canker), number of cankers, and five categories of

125 seedling vigor (vigorous; moderately vigorous; sickly; dead from WPBR; dead from non-WPBR

126 causes). The presence/absence of pycnia was noted at $3^{\text {rd }}$ assessment (April). In May 2015 after

127 the third assessment, the severely cankered seedlings were destructively sampled for separate

128 work related to a comparative genomic study of MGR between northern and southern

129 populations. Only those seedlings that were canker-free or had less severe cankers at the $3^{\text {rd }}$

130 assessment (and not destructively sampled) were assessed a fourth time (November). Canker-

131 free seedlings were left for further observation.

132 Statistical tests were performed using R version 3.2.2 software (R Core Team 2015). Binomial

133 tests were performed to see if any families differed from a 1:1 segregation in cankered and

134 canker-free traits that would suggest control by a single major dominant gene such as $\mathrm{Cr} 4$.

\section{Results}

136 Inoculation was successful with 267 of 270 of the seedlings showing needle spots (the first

137 symptom of infection) on primary needles at the first assessment. By second assessment (2

138 March) all seedlings had needle spots (Fig. 2). Most seedlings (267 of 270) had more than 10

139 needle spots at one or more inspection, with the majority ( 257 of 270 seedlings) having more

140 than 10 spots at first assessment (Fig. 2). Secondary needles also showed a high level of needle

141 spotting, with 40 of 44 seedlings having spots on secondary needles.

142 At the first assessment, most needle spots were classified as normal, yellow, and diffuse or

143 spreading (susceptible phenotype, Fig. 2c), but spots for 13 of the 267 seedlings were classified 
144 as 'some necrotic' $(n=1)$ or 'indeterminate' $(n=12)$ (Fig. 2b). All three seedlings with no spots 145 and 12 of the 13 seedlings with indeterminate spot type at the first assessment were progeny of 146 one Alberta parent tree, Prairie Bluff \#2. By second assessment all seedlings of twelve of the 13

147 families had distinctly susceptible spots (Table 1). In contrast, 15 seedlings of Prairie Bluff \#2 148 were still characterized as indeterminate (Table 1); two of the Prairie Bluff \#2 seedlings with 149 indeterminate spots in March were later characterized as having susceptible spots at third 150 assessment (23 April).

151 Stem infection was high for this trial; 100 percent of seedlings in 10 of the 13 families developed 152 cankers (Table 1, Fig. 2d), and two other families had greater than $85 \%$ cankering. Cankering 153 increased between January ( $1^{\text {st }}$ assessment $)$ and April ( $3^{\text {rd }}$ assessment $)$, and most of the observed 154 cankers were present by March ( $2^{\text {nd }}$ assessment). Overall, 53.0\%, 90.4\%, and 94.7\% of the 155 seedlings had cankers at the at $1^{\text {st }}, 2^{\text {nd }}$, and $3^{\text {rd }}$ assessments, respectively. Number of cankers per 156 seedling varied from 0 to 6,0 to 9 , and 0 to 9 at the $1^{\text {st }}, 2^{\text {nd }}$, and $3^{\text {rd }}$ assessment $(m e a n=0.77,2.95$, 157 and 3.33 cankers per seedling, respectively), although counting cankers became more difficult as 158 time progressed, and cankers began to merge. At the $3^{\text {rd }}$ assessment, pycnia were noted on 72.2 159 percent of cankered seedlings.

160 All of the families had a ratio of cankered to canker-free seedlings at $3^{\text {rd }}$ assessment significantly 161 different from 1:1 $(\mathrm{p}<0.0001)$ except for Prairie Bluff \#2 $(\mathrm{p}=0.26)$. This suggests that Prairie 162 Bluff \#2 is segregating for cankered and canker-free seedlings and is putatively heterozygous for 163 MGR. Prairie Bluff \#2 also showed a perfect correspondence between cankered/canker-free 164 seedlings and susceptible/necrotic spot type; in this trial, analysis of spot phenotype yields 165 identical results to analysis of cankered phenotype. Seven canker-free seedlings died from 
166 unknown causes during the trial; three of these were from Prairie Bluff \#3, three from Prairie 167 Bluff \#2, and one from Crowsnest Pass \#49.

168 Seedlings in Prairie Bluff \#2 (the putative MGR family) also tended to have fewer early needle 169 spots relative to the other families in this trial at the first assessment; nine of the 13 trees with 10 170 or fewer spots at first assessment were from this family. The odds of having ten or fewer spots at $1711^{\text {st }}$ assessment were significantly greater for this family than for the group of the other families $172(\mathrm{p}<0.0001$, Fisher's exact test $)$. The odds of having 10 or fewer spots at $1^{\text {st }}$ inspection were 173 estimated to be between 11 and 224 times greater for the MGR family (95\% confidence interval). 174 By second assessment, only four seedlings (including three from Prairie Bluff \#2) had 10 or 175 fewer needle spots.

176 Within the putative MGR family (Prairie Bluff \#2), the odds of developing cankers by the 3rd 177 inspection were significantly lower for the seedlings that had 10 or fewer spots at the $1^{\text {st }}$ 178 inspection ( $\mathrm{p}=0.015$ from two-sided test). None of the nine seedlings in this family with 10 or 179 fewer spots at first inspection displayed cankers later in the trial.

180 Mortality was first observed at $3^{\text {rd }}$ assessment, with 26 cankered seedlings dead and 4 seedlings 181 dead from unknown causes (three of these from Prairie Bluff \#3 and one from Prairie Bluff \#2). 182 Delayed mortality could be an indicator of partial resistance; however, trends in mortality over 183 time were not investigated in this trial because the majority of cankered seedlings were 184 destructively sampled in May 2015.

\section{Discussion}

186 Limber pine is very susceptible to WPBR both in its natural forest environment as well as in 187 inoculation trials utilizing young seedlings. However, only a few seedling inoculation trials have 
188 189

been undertaken to examine the types and frequency of resistance and its geographic distribution (Sniezko et al. 2011; Schoettle et al. 2014; Kinloch and Dupper 2002). In a trial including populations from the southern Rocky Mountains, the frequency of the $\mathrm{Cr} 4$ allele averaged five percent but varied from 0 to 13.9 percent over sites, and $14.3 \%$ of the 105 seed parents showed segregation ratios suggesting MGR (Schoettle et al. 2014).

This trial examined young seedling families from the northern part of the geographic range of limber pine for the presence of MGR. During the trial, 100 percent of the seedlings displayed needle infections, and only three of the 13 families had one or more canker-free seedlings, potential evidence of genetic resistance to WPBR. One of the families segregated 1:1 for cankered and canker-free seedlings, suggesting that one of the parent trees from Alberta has MGR, putatively from the same $\mathrm{Cr} 4$ gene identified in southern populations in earlier trials at DGRC (Schoettle et al. 2014). Spots on the canker-free seedlings in this family (Prairie Bluff \#2) were characterized as "questionable" because they were not spreading like a susceptible spot yet lacked the necrotic ring typical of spots on canker-free MGR seedlings in other white pine species such as western white pine and sugar pine (Fig. 2a, 2b). However, the spots were similar to those noted in our previous trials of limber pine from southern populations (Schoettle et al. 2014). The spots on the MGR seedlings in Prairie Bluff \#2 in this trial appeared as defined, discrete, and brown compared with the normal spreading yellow susceptible spots on cotyledons and primary and secondary needles (Fig. 2). The necrotic spot phenotype could generally be used to indicate MGR in limber pine, but canker-free status would provide additional confirmation. Many of the canker-free seedlings in this family also showed latency in the development of needle spots, having ten or fewer spots at first assessment. Although in this study the latency was primarily observed in seedlings with the MGR phenotype, future studies will be needed to 
211 confirm its relationship with MGR. Two other seedling families showed just one to three canker-

212 free seedlings (out of 21 seedlings tested), suggesting that those parent trees are susceptible but

213 may have been pollinated by a MGR parent tree in the vicinity or have some other type of

214 resistance. One of these two parent trees (Prairie Bluff \#3) is located $\sim 100 \mathrm{~m}$ from the MGR

215 parent (Prairie Bluff \#2) identified here, and presumably pollen exchange could easily occur

216 between these two trees. However, it is notable that those four seedlings never showed the

217 necrotic spot type. The populations for these three families are in southern Alberta and British

218 Columbia, and previous surveys have shown these areas to have very high levels of WPBR

219 infection in the vicinity of the parent trees. Progeny of canker-free parent trees in highly infected

220 stands can be strong candidates to show genetic resistance in inoculation trials since a high level

221 of natural 'pre-screening' has been done in the forest.

222 To our knowledge, this is the first report of MGR to WPBR in Canada in natural populations of

223 any of the four white pine species present there (P. flexilis, P. monticola, P. albicaulis, and $P$.

224 strobus), the first report of any type of genetic resistance to WPBR in the northernmost

225 populations of limber pine, and the northern-most known incidence of putative R-gene resistance

226 in a population of any five-needle pine species. Prior to this report, MGR in limber pine had

227 only been confirmed to be present in some populations present in Colorado and Wyoming. The

228 results here extend the known geographic range of MGR, putatively affiliated with the same $\mathrm{Cr} 4$

229 gene as that of the Colorado and Wyoming populations, to one of the northern-most populations

230 of the species, $>700 \mathrm{~km}$ north of the previously documented occurrence of $\mathrm{Cr} 4$. In the other three

231 species of white pines where MGR has been documented, there has been no confirmation of

232 MGR in the northern-most populations (Kinloch 1992; Kinloch et al. 2003; Sniezko,

233 unpublished). The previous northernmost documentation of MGR in any of the North American 
234 species was in P. monticola in southern Washington (Kinloch et al. 2003), more than $250 \mathrm{~km}$

235 south of the Prairie Bluff \#2 parent tree. Future genetic mapping efforts will help determine

236 whether MGR in the Alberta population is due to the same gene $(\mathrm{Cr} 4)$ noted previously in limber

237 pine or to a separate R-gene.

238 Surveys of several of the Canadian populations whose progeny were tested here have indicated 239 that 85 to 96 percent of the trees are infected or dead from WPBR. WPBR cankers had been 240 noted on four of the 10 Canadian parent trees whose progeny were evaluated here, and 100 241 percent of the seedling progeny of those parents were cankered in this trial. It should also be 242 noted that progeny of only one or two parent trees per population was evaluated in this trial; it is 243 possible that other parent trees within the population may have MGR or other types of genetic 244 resistance. Finding one parent with MGR is encouraging, but the susceptibility of the progeny of 245 the other parents from these native stands with high infection levels suggests that (a) even higher 246 infection and mortality will occur in those stands, or (b) resistances other than MGR (e.g. partial 247 resistance) may be present and difficult to detect in the very young, small seedlings utilized here.

248 The eastern Oregon population of limber pine represents an outlying, disjunct population at the 249 northwestern-most portion of the species range. The three families tested showed no indication 250 of MGR.

251 Complete resistance from a major (single, dominant) gene has been found in four of the nine 252 species of white pines present in the U.S. (Kinloch and Dupper 2002; Kinloch et al. 2003;

253 Schoettle et al. 2014). More extensive trials are now underway at DGRC to examine the 254 frequency and geographic distribution of MGR and partial resistance to WPBR in limber pine. 
255 The information from these trials will provide key knowledge to help resource managers better 256 manage their populations.

257 To be of maximum utility, genetic resistance in limber pine has to be durable. Virulence to MGR 258 has been previously documented in P. monticola and P. lambertiana (Kinloch and Dupper 2002;

259 Kinloch et al. 2004) but not in either P. flexilis or P. strobiformis thus far. Limber pine parent 260 trees identified as having MGR can serve as monitors for the potential evolution of virulence or a 261 change in efficacy of this type of resistance with a changing climate. In addition, parent trees 262 identified as susceptible can serve as monitors of the spread or intensification of WPBR. The 263 data from such monitoring will provide managers with information to guide recovery efforts of 264 this species in Alberta and restoration efforts throughout the range of limber pine.

\section{Acknowledgements}

266 Andy Bower and Chris Jensen collected the Oregon seedlots. Randy Moody, Mike Keefer and 267 Don Pigott selected the trees and/or collected the Canadian seed, except for 1999 collection 268 made by personnel of Quality Seeds from Kamloops, and the two Crowsnest Pass trees collected 269 by personnel from Alberta Tree Improvement and Seed Centre (ATISC). Dave Kolotelo and 270 Don Pigott provided information on the geographic locations of the Canada parent trees. Jodie

271 Krakowski, Don Pigott and Barb Gass provided information on relative levels of WPBR

272 infection in the Canadian populations and/or on the individual trees. Technicians and staff at

273 DGRC assisted with different phases of the study. Thanks to Brianna McTeague for construction 274 of the map and reviewing an earlier version of this paper. We thank the five anonymous 275 reviewers for their suggestions. 


\section{References}

278 Alberta Whitebark and Limber Pine Recovery Team. 2014. Alberta limber pine recovery plan 279 2014-2019. Alberta Environment and Sustainable Resource Development. Alberta Species at 280 Risk Recovery Plan No. 35. Edmonton, AB. 61pp. http://esrd.alberta.ca/fish-wildlife/species-at281 risk/species-at-risk-publications-web-resources/plants/documents/SAR-LimberPine-

282 RecoveryPlan-Sep2014.pdf [accessed 15 February 2016].

283 COSEWIC. 2014. COSEWIC assessment and status report on the Limber Pine Pinus flexilis in

284 Canada. Committee on the Status of Endangered Wildlife in Canada. Ottawa. ix +49 pp.

285 http://www.registrelep-sararegistry.gc.ca/document/default e.cfm?documentID=2759 [accessed 28615 February 2016].

287 Government of Alberta. 2014. Species assessed by Alberta's Endangered Species Conservation 288 Committee: short list [online]. Available from http://aep.alberta.ca/fish-wildlife/species-at289 risk/documents/SpeciesAssessed-Endangered-Jul18-2014.pdf [accessed 15 February 2016].

290 Kinloch, B.B., Jr. 1992. Distribution and frequency of a gene for resistance to white pine blister 291 rust in natural populations of sugar pine. Can. J. Bot. 70: 1319-1323.

292 Kinloch B.B., Jr., and Dupper G.E. 2002. Genetic specificity in the white pine-blister rust 293 pathosystem. Phytopathology. 92: 278-280. doi: 10.1094/PHYTO.2002.92.3.278.

294 Kinloch, B.B., Jr., Sniezko, R.A. and Dupper, G.E. 2003. Origin and distribution of Cr2, a gene 295 for resistance to white pine blister rust in natural populations of western white pine.

296 Phytopathology. 93: 691-694. doi: 10.1094/PHYTO.2003.93.6.691. 
297 Kinloch, B.B., Jr., Sniezko, R.A., and Dupper, G.E. 2004. Virulence gene distribution and 298 dynamics of the white pine blister rust pathogen in western North America. Phytopathology. 94: 299 751-758. doi: 10.1094/PHYTO.2004.94.7.751.

300 301 302 303 304 305 306 307

R Core Team. 2015. R: A language and environment for statistical computing. R Foundation for Statistical Computing, Vienna, Austria. https://www.R-project.org/.

Schwandt, J.W., Lockman, I.B. Kliejunas, J.T. and Muir, J.A. 2010. Current health issues and management strategies for white pines in the western United States and Canada. Forest Pathology 40: 226-250. doi: 10.1111/j.1439-0329.2010.00656.x.

Schoettle, A.W., Sniezko, R.A., Kegley, A., and Burns, K.S. 2014. White pine blister rust resistance in limber pine: evidence for a major gene. Phytopathology. 104: 163-73. doi:10.1094/PHYTO-04-13-0092-R.

Smith, C.M., Langor, D., Myrholm, C., Weber, J., Gillies, C., and Stuart-Smith, J. 2011. Limber pine health in the Canadian Rockies. In Proceedings of the High Five Symposium: the Future of High-elevation, Five-needle White Pines in Western North America, 28-30 June 2010, Missoula, Montana. Edited by R.E. Keane, D.F. Tomback, M. Murray, and C.M. Smith. US For. Serv. RMRS-P-63. pp. 63-65. Available from http://www.fs.fed.us/rm/pubs/rmrs_p063.html [accessed 5 February 2016].

Smith, C.M., Langor, D.W., Myrholm, C., Weber, J., Gillies, C., and Stuart-Smith, J. 2013. Changes in white pine blister rust infection and mortality in limber pine over time. Can J For Res. 43(10): 919-928. doi: 10.1139/cjfr-2013-0072.

Sniezko, R.A., Mahalovich, M.F., Schoettle, A.W., and Vogler, D.R. 2011. Past and current investigations of the genetic resistance to Cronartium ribicola in high-elevation five-needle 
319 pines. p. 246-264, in Keane, Robert E.; Tomback, Diana F.; Murray, Michael P.; and Smith, 320 Cyndi M., eds. 2011. The future of high-elevation, five-needle white pines in Western North 321 America: Proceedings of the High Five Symposium. 28-30 June 2010; Missoula, MT.

322 Proceedings RMRS-P-63. Fort Collins, CO: U.S. Department of Agriculture, Forest Service, 323 Rocky Mountain Research Station. 376 p. Online at

324 http://www.fs.fed.us/rm/pubs/rmrs_p063.html [accessed 15 February 2016].

325 Steele, R. 1990. Pinus flexilis James. In Silvics of North America: 1. Conifers; R.M. Burns, and 326 B.H. Honkala, tech. coords. 1990. Agriculture Handbook 654. U.S. Department of Agriculture, 327 Forest Service, Washington, DC. pp. 348-354.

328 http://www.na.fs.fed.us/spfo/pubs/silvics_manual/Volume_1/pinus/flexilis.htm [accessed 15 329 February 2016].

330 Tomback, D.F. and Achuff, P. 2010: Blister rust and western forest biodiversity: Ecology, 331 values, and outlook for white pines. For. Pathol. 40: 186-225. doi: 10.1111/j.1439-

$332 \quad 0329.2010 .00655 . x$. 
334 Table 1. White pine blister rust infection (needle, stem) and mortality for 13 limber pine families.

\begin{tabular}{lccccc}
\hline $\begin{array}{l}\text { Population and Tree } \\
\text { number }\end{array}$ & $\begin{array}{c}\text { Number } \\
\text { seedlings }\end{array}$ & $\begin{array}{c}\text { Number with } \\
\text { susceptible } \\
\text { needle spots }\end{array}$ & $\begin{array}{c}\text { Number } \\
\text { dead (non- } \\
\text { rust) }\end{array}$ & $\begin{array}{c}\text { Number } \\
\text { cankered }\end{array}$ & $\begin{array}{c}\text { Mean } \\
\text { number of } \\
\text { cankers }^{b}\end{array}$ \\
\hline Kicking Horse \#1 & 21 & 21 & 0 & 21 & 4.0 \\
Andy Good Creek \#123 & 22 & 22 & 0 & 22 & 2.5 \\
Andy Good Creek \#151 & 17 & 17 & 0 & 17 & 2.1 \\
Crowsnest Pass \#49 & 21 & 21 & $1^{c}$ & 20 & 2.8 \\
Crowsnest Pass \#51 & 21 & 21 & 0 & 21 & 3.5 \\
Prairie Bluff \#2 & 21 & 7 & $2^{c}, 1^{d}$ & 7 & $0.78\left(2.0^{e}\right)$ \\
Prairie Bluff \#3 & 21 & 21 & $3^{d}$ & 18 & 2.1 \\
Kananaskis \#9 & 21 & 21 & 0 & 21 & 2.8 \\
Abraham Lake \#1 & 21 & 21 & 0 & 21 & 3.5 \\
Abraham Lake \#8 & 21 & 21 & 0 & 21 & 4.3 \\
Hurricane \#1 & 21 & 21 & 0 & 21 & 5.0 \\
Hurricane \#3 & 21 & 21 & 0 & 21 & 3.5 \\
Hurricane \#6 & 21 & 21 & 0 & 21 & 5.6 \\
\hline S & 21 & & & & \\
\hline
\end{tabular}

${ }^{a}$ See text for discussion of rust-related mortality.

${ }^{b}$ Mean number of cankers is based on the maximum number of cankers observed for any assessment on individual seedlings, excluding dead (non-rust) trees.

$339{ }^{d}$ Dead at $3^{\text {rd }}$ assessment (no canker).

$340{ }^{e}$ Mean number of cankers excluding dead (non-rust) and canker-free trees. 
342 Figure 1. Locations of limber pine seed trees of 13 seedling families tested for blister rust resistance at 343 Dorena Genetic Resource Center. Previous locations (Wyoming and Colorado) where major gene 344 resistance (MGR) in limber pine had been documented are indicated with ' $X$ ' in the small insert map 345 (Limber pine range data from Whitebark Pine Ecosystem Foundation. 2014. Available online from 346 http:(whitebarkfound.org.).

347 Figure 2. Differential MGR spot types on canker-free seedlings of (a) western white pine and (b) limber 348 pine family Prairie Bluff \#2. Also shown is a limber pine seedling with yellow, susceptible type needle 349 spots typical on cankered seedlings (c) and a heavily cankered seedling (d). 


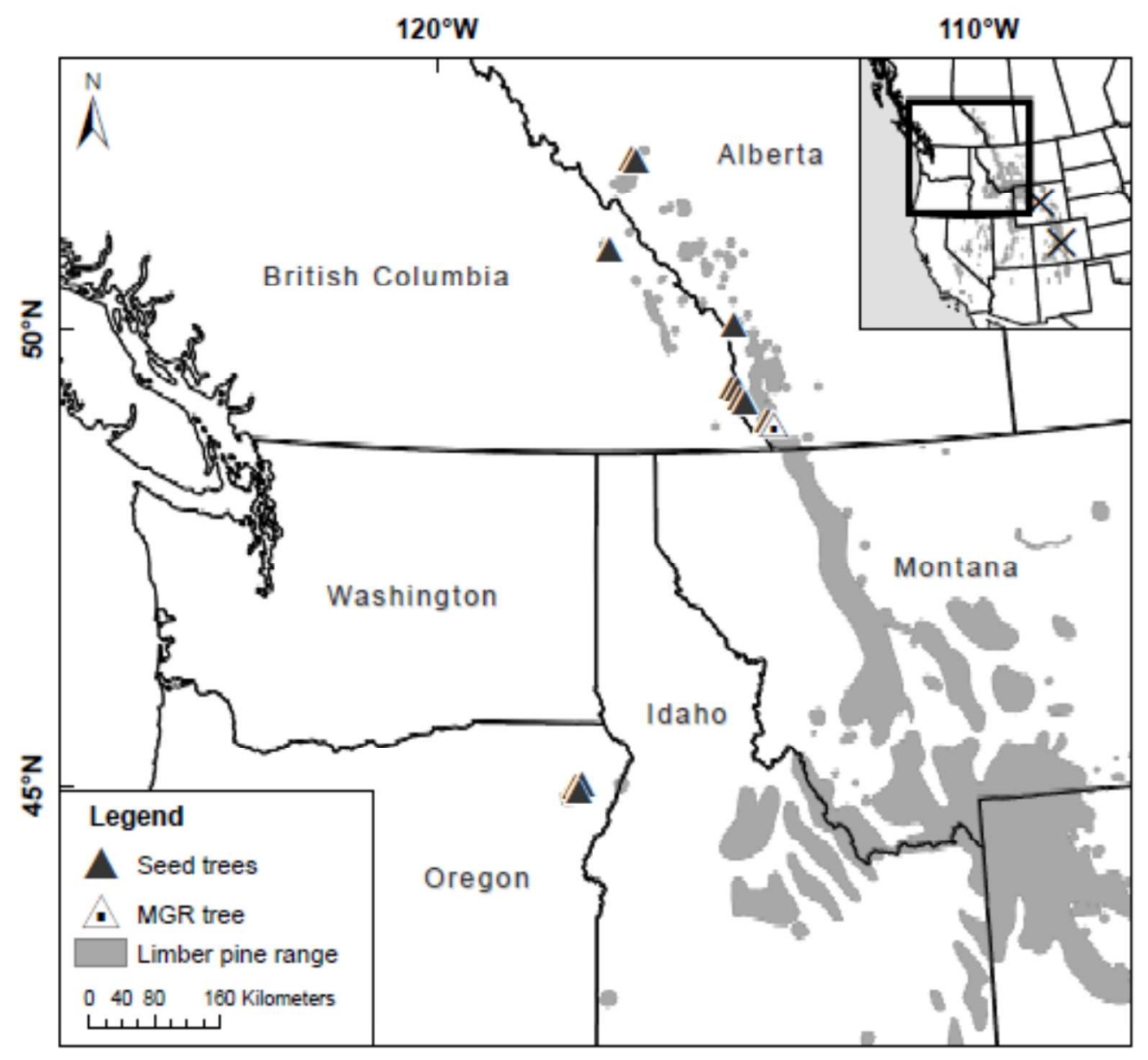

351 
Figure 2.

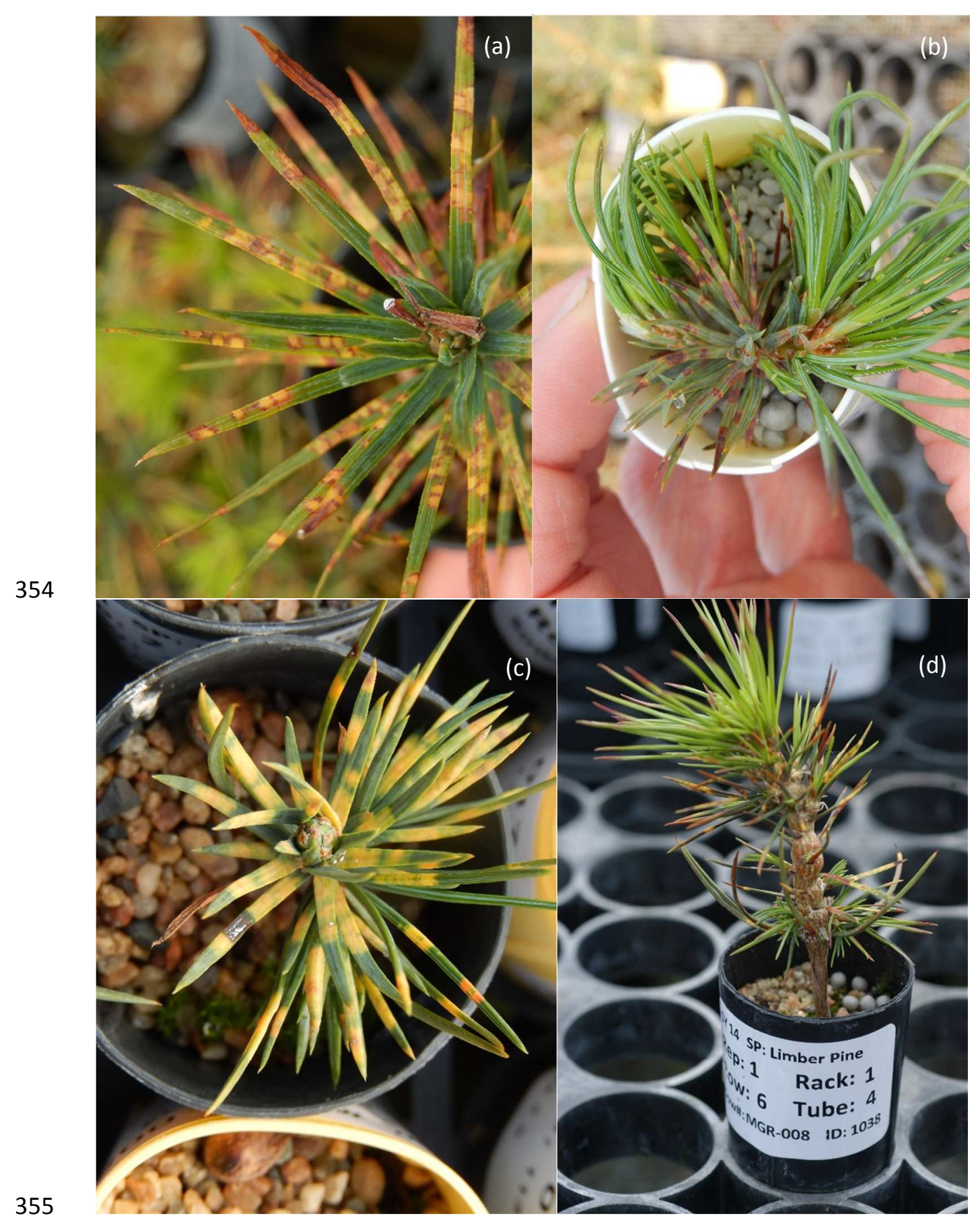

